\title{
O ESTÁGIO SUPERVISIONADO EM EDUCAÇÃO INFANTIL E A FORMAÇÃO DOCENTE EM EDUCAÇÃO FÍSICA
}

\author{
Rodrigo Lema Del Rio Martins ${ }^{1}$, \\ Luiza Fraga Tostes², André da Silva Mello ${ }^{3}$
}

\section{RESUMO}

Este artigo analisa as disciplinas de Estágio Supervisionado relacionadas à Educação Infantil nos cursos de Licenciatura em Educação Física, identificando os pontos de convergência e de divergência com as orientações pedagógicas contidas nos documentos norteadores da primeira etapa da Educação Básica. Trata-se de uma pesquisa documental que utiliza como fontes as ementas e as bibliografias das referidas disciplinas em cursos oferecidos por universidades públicas, sediadas nas capitais brasileiras, em que há a presença de professores de Educação Física atuando na Educação Infantil municipal. Foram examinadas 16 ementas e 267 obras vinculadas a elas, provenientes de currículos de 14 universidades. O estudo constata um afastamento dessas ementas e bibliografias com relação aos documentos oficiais que balizam o trabalho pedagógico na Educação Infantil no país. Conclui-se que esse distanciamento pode acarretar dificuldades para a ampliação da presença do professor com formação em Educação Física na primeira etapa da Educação Básica e, também, para a sua permanência.

Palavras-chave: Educação Infantil. Educação Física. Formação inicial. Estágio Supervisionado. Documentos orientadores.

\section{Como citar este documento - ABNT}

MARTINS, Rodrigo Lema Del Rio; TOSTES, Luiza Fraga; MELLO, André da Silva. O estágio supervisionado em Educação Infantil e a formação docente em Educação Física. Revista Docência do Ensino Superior, Belo Horizonte, v. 10, e015181, p. 1-18, 2020 DOI: https://doi.org/10.35699/2237-5864.2020.15181.

Recebido em: 08/09/2019 Aprovado em: 20/01/2020 Publicado em: 05/05/2020

\footnotetext{
${ }^{1}$ Universidade Federal do Tocantins (UFT), Palmas, TO, Brasil. ORCID: https://orcid.org/0000-0002-1082-2425. E-mail: rodrigodrmartins@uft.edu.br.

${ }^{2}$ Universidade Federal do Espírito Santo (UFES), Vitória, ES, Brasil.

ORCID: https://orcid.org/0000-0002-0402-3248. E-mail: lufragatostes@gmail.com.

${ }^{3}$ Universidade Federal do Espírito Santo (UFES), Vitória, ES, Brasil.

ORCID: https://orcid.org/0000-0003-3093-4149. E-mail: andremellovix@gmail.com.
} 
LA ETAPA DE SUPERVISIÓN EN LA EDUCACIÓN INFANTIL Y LA EDUCACIÓN DEL PROFESOR EN LA EDUCACIÓN FÍSICA

\section{RESUMEN}

Este artículo analiza las disciplinas de pasantías supervisadas relacionadas con los cursos de grado de Educación Infantil en Educación Física, identificando los puntos de convergencia y divergencia con las pautas pedagógicas contenidas em los documentos guías de la primera etapa de la educación básica. Esta es una investigación documental, que utiliza como fuentes los menús y las bibliografías de estas disciplinas en los cursos ofrecidos por las universidades públicas, ubicadas en las capitales brasileñas en las que existe la presencia de docentes de educación física que actúan en la educación municipal de la primera infancia. Se examinaron dieciséis menús y 267 obras relacionadas de 14 planes de estudio universitarios. El estudio encuentra una desviación de estos menús y bibliografías en relación con los documentos oficiales que guían el trabajo pedagógico en la educación de la primera infancia en el país. Concluye que esta distancia puede generar dificultades para la expansión de la presencia de docentes con formación en Educación Física en la primera etapa de la Educación Básica y, también, para su permanencia.

Palabras clave: Educación física. Educación Infantil. Formación inicial. Prácticas Supervisadas. Documentos de guia.

\section{SUPERVISED INTERNSHIP IN CHILDHOOD EDUCATION AND TEACHER TRAINING IN PHYSICAL EDUCATION}

\section{ABSTRACT}

This article analyzes the Supervised Internship disciplines related to Early Childhood Education in Physical Education degree courses, identifying the points of convergence and divergence with the pedagogical guidelines contained in the guiding documents of the first stage of Basic Education. This is a documentary research, which uses as sources the menus and bibliographies of these disciplines in courses offered by public universities, located in Brazilian capitals, in which there are Physical Education teachers working in municipal Early Childhood Education. Sixteen menus and 267 related works from 14 university curricula were examined. The study finds a departure from these menus and bibliographies in relation to the official documents that guide the pedagogical work in Early Childhood Education in the country. It concludes that this distance may lead to difficulties for the expansion of the presence of teachers with training in Physical Education in the first stage of Basic Education and, also, for their permanence.

Keywords: Physical Education. Childhood education. Guiding documents. Initial formation. Supervised Internship. 


\section{INTRODUÇÃO}

O Estágio Supervisionado é uma exigência para a formação docente, devendo ser cumprido por todos os estudantes das licenciaturas, como condição para sua futura atuação profissional. No âmbito da Educação Física, os licenciandos precisam perfazer, no mínimo, 400 horas de Estágio sob a supervisão e coordenação de professores das unidades de Educação Básica e da Instituição de Ensino Superior (IES) promotora do curso.

Biscosni e Oliveira (2016) destacam que o Estágio Supervisionado é um importante momento formativo para os futuros professores, por meio do qual é possível refletir sobre os desafios e as possibilidades de proposições pedagógicas aprendidas nos cursos de licenciatura, além de repensar práticas e saberes vivenciados quando estavam na condição de estudantes da Educação Básica. Esse processo de dialetizar sobre os saberes curriculares, oriundos de sua bagagem histórica e cultural como indivíduos, e os saberes da formação profissional, provenientes do ensino-aprendizagem dos conhecimentos específicos de uma determinada área, é destacado por Tardif (2007) como fundamental para a constituição da atividade docente.

O Estágio Supervisionado curricular nas licenciaturas é um valioso momento de interlocução entre as docências do/no Ensino Superior e da/na Educação Básica, capaz de aproximar a universidade e as escolas, ampliando os contextos de aprendizagem da profissão. Os processos formativos desencadeados a partir da interação entre os diferentes sujeitos envolvidos (orientadores de estágio dos cursos, supervisores de estágio nas escolas e discentes em formação inicial) favorecem um movimento dinâmico de formação recíproca e crescimento mútuo, que representa uma via de mão dupla em que tanto a escola, quanto a universidade aprendem e ensinam ao mesmo tempo, retroalimentando a relação entre teoria e prática.

Os dilemas, tensões, desafios e possibilidades que cercam o processo de formação inicial, mediados pelo Estágio Supervisionado, são potencializados quando pensamos a licenciatura em Educação Física e a atuação profissional na Educação Infantil. Isso porque se trata de uma etapa da Educação Básica que não se organiza de forma disciplinar, prezando pela construção de conhecimento não fragmentado, segundo seus principais documentos norteadores: Diretrizes Curriculares Nacionais para a Educação Infantil (DCNEIs) e Base Nacional Comum Curricular (BNCC) (BRASIL, 2013, 2017). Por esse ângulo, a presença de professores com formação específica em Educação Física lecionando nesse contexto torna-se questionável.

O que tem sido possível apreender, por meio de pesquisas com foco na docência da Educação Física na Educação Infantil e em cursos de licenciatura no referido campo, é que a presença dessa área de conhecimento na primeira etapa da Educação Básica tem sido impulsionada por questões legais, administrativas e, sobretudo, pedagógicas (MARTINS, 2018). Um indício 
relevante a esse respeito é o fato de um número significativo de cursos de licenciatura em Educação Física dedicar, em seus currículos, uma disciplina para tratar das questões relativas ao Estágio Supervisionado voltado para a Educação Infantil (MARTINS, 2018).

A produção de conhecimento sobre a relação entre Educação Física e Educação Infantil também tem se mostrado bastante consistente, com expansão considerável nas duas últimas décadas (MELLO et al., 2012; MARTINS, 2018). Por outro lado, Martins, Tostes e Mello (2018) asseguram haver poucas pesquisas que investigam os processos de formação inicial em Educação Física voltada para a atuação profissional na Educação Infantil.

Diante desse cenário, consideramos relevante debater como a formação em Educação Física para a atuação profissional na Educação Infantil tem se delineado, provocando reflexões acerca da relação entre a docência no Ensino Superior e o diálogo com as demandas do campo profissional. Problematizamos o modo como as discussões sobre a docência e a infância vêm se estruturando no Ensino Superior, por meio do Estágio Supervisionado, levantando questões que podem, inclusive, ser apropriadas pelos Núcleos Docentes Estruturantes (NDEs) das universidades para (re)pensar os processos de ensino-aprendizagem nos cursos de licenciatura.

Assim sendo, nosso objetivo é analisar as ementas e as bibliografias de disciplinas de Estágio Supervisionado associadas à Educação Infantil nos cursos de formação inicial em Educação Física. Assim, identificaremos os pontos de convergência e de divergência que elas estabelecem com os documentos norteadores dessa primeira etapa da Educação Básica (DCNEls e BNCC), que apontam para o reconhecimento da criança como sujeito de direitos, produtora de cultura e protagonista em seus processos de socialização.

\section{METODOLOGIA}

Para cumprir o objetivo proposto neste artigo, adotamos a pesquisa documental. Pimentel (2001) afirma que estudos dessa natureza são desenvolvidos por meio de documentos, contemporâneos ou retrospectivos, e têm sido amplamente utilizados nas Ciências Sociais com a finalidade de descrever e/ou comparar fatos sociais, estabelecendo suas características e tendências.

Trata-se de uma pesquisa documental, parte de uma investigação mais ampla aprovada pelo Comitê de Ética em Pesquisa da Universidade Federal do Espírito Santo (Parecer no 2.457.294), que utiliza como fontes as ementas e as bibliografias das disciplinas relacionadas com a Educação Infantil dos cursos de licenciatura em Educação Física de universidades públicas do país, sediadas nas capitais brasileiras, em que há a presença de professores de Educação Física 
atuando na primeira etapa da Educação Básica pública municipal, conforme levantamento publicado por Martins, Tostes e Mello (2018). ${ }^{4}$

Escolhemos as universidades públicas devido às pesquisas desenvolvidas por essas instituições no contexto nacional e pela influência regional que elas exercem na formação docente nas cidades e nos estados em que estão sediadas. O recorte pelas capitais está ancorado em nossa hipótese de que essas cidades detêm certa capacidade de propagação das políticas públicas - entre elas as educacionais - para outras cidades. Tal propagação estendese a prováveis parcerias pontuais e/ou mais duradouras que as universidades costumam estabelecer com o Poder Público a fim de oportunizar campos de pesquisa, ensino e extensão, promovendo a aproximação e a interlocução entre os sujeitos da Universidade e da Educação Básica.

De acordo com a plataforma e-MEC, ${ }^{5}$ são 19 universidades públicas brasileiras que se enquadram no critério definido para este estudo. ${ }^{6}$ As ementas e as bibliografias foram acessadas nos sites oficiais das IES, por meio de telefonemas e/ou mensagens eletrônicas (email) às coordenações de curso. A única instituição sobre a qual não obtivemos informações foi a IFRR. Por essa razão, ela foi excluída das análises.

O corpus deste estudo é constituído por 16 ementas que focalizam questões relacionadas às práticas pedagógicas e 267 obras vinculadas a elas, entre artigos, documentos oficiais, livros, capítulos de livros, teses e dissertações. No processo de análise, utilizamos o software Iramuteq ${ }^{7}$ (CAMARGO; JUSTO, 2013) para realizar um tratamento qualiquantitativo dos dados

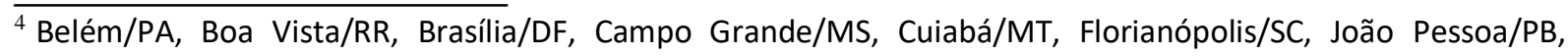
Manaus/AM, Palmas/TO, Porto Alegre/RS, Recife/PE, Rio de Janeiro/RJ e Vitória/ES. Importante frisar que esse quadro pode ter se alterado, tendo em vista que, em 2016, tivemos eleições municipais, e isso pode ter gerado a assunção de novos prefeitos que nem sempre dão continuidade às políticas públicas de seus antecessores.

${ }^{5}$ Nessa base de dados, é possível consultar as informações sobre as IES e sobre os cursos de graduação reconhecidos pelo Ministério da Educação em todo o território nacional (Disponível em: http://emec.mec.gov.br/. Acesso em: 21 abr. 2017).

${ }^{6}$ Universidade Federal do Rio Grande do Sul (UFRGS), Universidade Federal de Santa Catarina (UFSC), Universidade para o Desenvolvimento do Estado de Santa Catarina (UDESC), Universidade Federal do Rio de Janeiro (UFRJ), Universidade Estadual do Rio de Janeiro (UERJ), Universidade Federal do Espírito Santo (UFES), Universidade de Brasília (UnB), Universidade Federal do Mato Grosso (UFMT), Universidade Federal do Mato Grosso do Sul (UFMS), Universidade Federal de Pernambuco (UFPE), Universidade Federal Rural de Pernambuco (UFRPE), Universidade Estadual de Pernambuco (UPE), Universidade Federal da Paraíba (UFPB), Universidade Federal do Pará (UFPA), Universidade Estadual do Pará (UEPA), Universidade Estadual de Roraima (UERR), Instituto Federal de Roraima (IFRR), Universidade Federal do Amazonas (UFAM), Universidade Estadual do Amazonas (UEA). Embora Palmas/TO seja uma capital brasileira na qual identificamos a presença de professores de Educação Física atuando na Educação Infantil pública municipal, a Universidade Federal de Tocantins possui o Curso de Licenciatura em Educação Física em cidades do interior (Miracema e Tocantinópolis) e o Instituto Federal do Tocantins (IFTO) possuía apenas a modalidade do Parfor.

${ }^{7}$ Software gratuito e com fonte aberta, desenvolvido pelo Prof. Dr. Pierre Ratinaud, do Laboratório de Estudos e Pesquisas Aplicadas em Ciências Sociais, da Universidade de Toulouse III, que realiza análises sobre corpus textuais. Essas análises têm várias finalidades, sendo possível examinar textos, entrevistas, documentos, redações etc.
} 
que, depois de processados, foram analisados por meio da nuvem de palavras e pela análise de similitudes.

A nuvem de palavras agrupa os vocábulos e organiza-os graficamente em função da sua frequência. Cabe ressaltar que o software Iramuteq só faz registro das palavras que foram mencionadas pelo menos três vezes no corpus textual examinado. A análise de similitudes está ancorada na teoria dos grafos (elementos combinatórios) e permite identificar as coocorrências entre as palavras e a conexidade que há entre elas, auxiliando na identificação da estrutura do texto (CAMARGO; JUSTO, 2013). Esses métodos combinados contribuem para compreender quais são as tendências, características e ausências de itens lexicais no material analisado.

No processo de análise dos dados, estabelecemos diálogos entre as ementas e as bibliografias e discutimo-nos com a literatura científica da área e os documentos oficiais (DCNEls e BNCC). O software permitiu produzir uma metanálise dos documentos trabalhados, ou seja, realizar um exame geral do corpus textual utilizado em um quadro interpretativo mais amplo, complementando com alguns excertos das ementas.

\section{APRESENTAÇÃO E ANÁLISE DOS DADOS}

Em relação às universidades selecionadas pelo critério disposto na metodologia deste estudo, as suas respectivas disciplinas que se constituem como alvo de interesse desta pesquisa estão apresentadas no Quadro 1, a seguir:

\begin{tabular}{|c|c|c|}
\hline IES & DISCIPLINAS & FORMATO \\
\hline \multicolumn{3}{|c|}{ Região Norte } \\
\hline UEA & Não tem uma disciplina específica sobre estágio & - \\
\hline UFAM & Estágio I: Educação Infantil & $\begin{array}{c}\text { Obrigatória - 30 período } \\
-105 \mathrm{~h}\end{array}$ \\
\hline UEPA & Estágio Curricular Supervisionado I & $\begin{array}{c}\text { Obrigatória - } 5 \text { o período } \\
-120 \mathrm{~h}\end{array}$ \\
\hline UFPA & Não tem uma disciplina específica sobre estágio & - \\
\hline UERR & Estágio Supervisionado I & $\begin{array}{c}\text { 5e período - Obrigatória } \\
-100 \mathrm{~h}\end{array}$ \\
\hline \multicolumn{3}{|c|}{ Região Nordeste } \\
\hline UPE & Prática de Ensino - Estágio Supervisionado I & $\begin{array}{c}\text { Obrigatória - 50 período } \\
-126 \mathrm{~h}\end{array}$ \\
\hline UFPE & Estágio Supervisionado em Educação Física I & $\begin{array}{c}\text { 60 Período - Obrigatória } \\
-90 \mathrm{~h}\end{array}$ \\
\hline UFRPE & Estágio Supervisionado I & $\begin{array}{c}\text { 5e Período - Obrigatória } \\
-90 \mathrm{~h}\end{array}$ \\
\hline UFPB & Estágio Profissional Supervisionado I & $\begin{array}{c}\text { 5o período - Obrigatória } \\
-150 \mathrm{~h}\end{array}$ \\
\hline
\end{tabular}




\begin{tabular}{|c|c|c|}
\hline \multicolumn{3}{|c|}{ Região Centro-oeste } \\
\hline UnB & Não tem uma disciplina específica sobre estágio & - \\
\hline UFMT & Estágio Supervisionado I & $\begin{array}{c}\text { Obrigatória - 5o Período } \\
-96 \mathrm{~h}\end{array}$ \\
\hline UFMS & $\begin{array}{l}\text { Estágio Obrigatório em Educação Física na Educação } \\
\text { Infantil }\end{array}$ & $\begin{array}{c}\text { Obrigatória - } 6 \text { 9 período } \\
-100 \mathrm{~h}\end{array}$ \\
\hline \multicolumn{3}{|c|}{ Região Sudeste } \\
\hline UERJ & Estágio supervisionado I: Educação Infantil & Optativa - 30h \\
\hline UFRJ & Não tem uma disciplina específica sobre estágio & - \\
\hline UFES & $\begin{array}{l}\text { Estágio Supervisionado em Educação Física na } \\
\text { Educação Infantil }\end{array}$ & $\begin{array}{c}\text { Obrigatória - 5 período } \\
-100 \mathrm{~h}\end{array}$ \\
\hline \multicolumn{3}{|c|}{ Região Sul } \\
\hline UDESC & Estágio Curricular I: Educação Física Infantil & $\begin{array}{c}\text { Obrigatória - 50 período } \\
-90 \mathrm{~h}\end{array}$ \\
\hline UFSC & Estágio Supervisionado em Educação Física I & $\begin{array}{l}\text { Obrigatória - Período } \\
\text { não informado - } 252 \mathrm{~h}\end{array}$ \\
\hline UFRGS & $\begin{array}{l}\text { Estágio em Docência da Educação Física em Educação } \\
\text { Infantil }\end{array}$ & $\begin{array}{c}\text { Obrigatória - 50 período } \\
-150 \mathrm{~h}\end{array}$ \\
\hline
\end{tabular}

Quadro 1 - Universidades e as disciplinas sobre Estágio Supervisionado em Educação Infantil Fonte: Elaborado pelos autores, 2019.

Das 18 universidades pesquisadas, em 14 delas encontramos disciplinas específicas sobre Estágio na Educação Infantil. Os textos completos das ementas e os autores presentes nas bibliografias foram inseridos, separadamente, no software Iramuteq, que gerou uma nuvem de palavras e similitudes específicas para as ementas e uma outra nuvem para as bibliografias.

A Figura 1, a seguir, apresenta as ementas das disciplinas de Estágio Supervisionado:

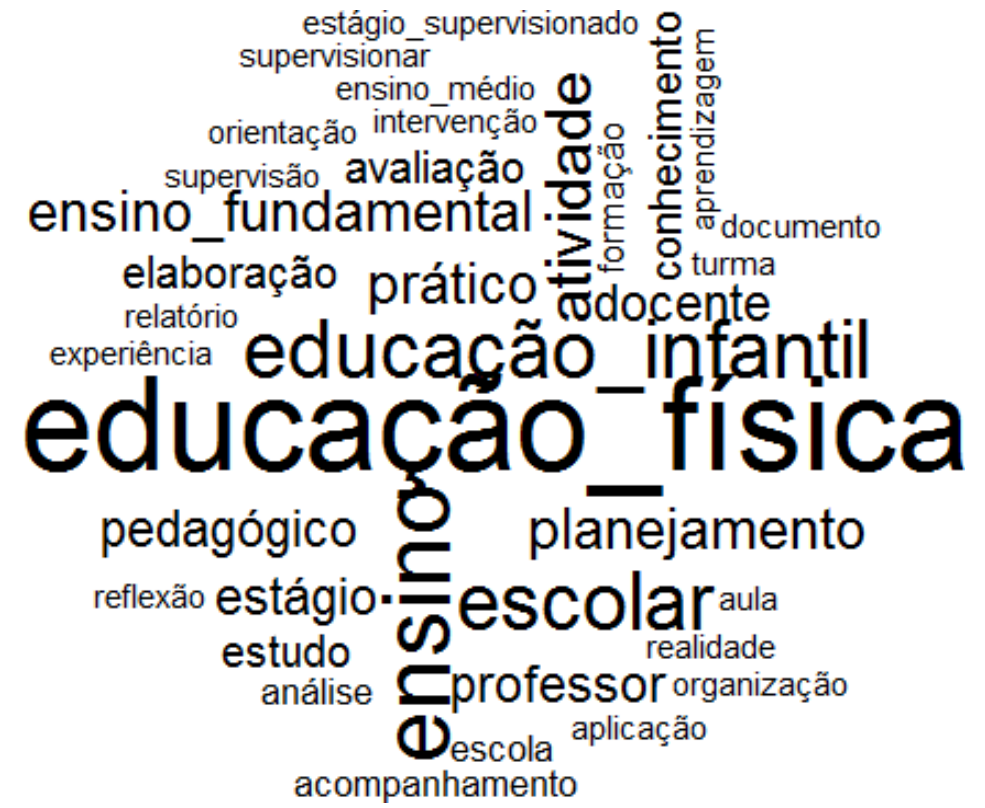

Figura 1 - Nuvem de palavras das ementas das disciplinas de Estágio Supervisionado Fonte: Elaborada pelos autores, 2019. 
As palavras Educação Física e Educação Infantil ocupam a região central da nuvem, em um tamanho destacado das demais, denotando a especificidade do objeto tratado nas referidas disciplinas.

Destacamos a recorrência da palavra "Ensino Fundamental" que, em muitos casos, está anunciada como escopo de uma mesma disciplina, conforme pode ser visto em cinco ementas (35,7\% do total):

Estágio supervisionado em Educação Física Escolar na Educação Básica [Educação Infantil, Ensino Fundamental ou Ensino Médio]. [...] elaboração e desenvolvimento de projeto de ensino em turmas de Educação Física na Educação Básica [Educação Infantil, Ensino Fundamental ou Ensino Médio] (ESTÁGIO SUPERVISIONADO EM EDUCAÇÃO FÍSICA I - UFSC).

Reflexões sobre a formação e atuação do professor de educação física nas práticas desenvolvidas no âmbito da Educação Infantil, Ensino Fundamental de 1ㅇ a 5을, Ensino fundamental de 6ㅇ a 9을 Ano e Ensino Médio (ESTÁGIO I: EDUCAÇÃO INFANTIL - UFAM).

Estágio supervisionado na Educação Básica da rede pública de ensino, nas modalidades de educação infantil e séries iniciais do ensino fundamental (ESTÁGIO CURRICULAR SUPERVISIONADO I: EDUCAÇÃO INFANTIL - UEPA).

Planejamento e direção de aulas de educação física na educação infantil e ensino fundamental (10 ciclo), sob orientação e supervisão docente (ESTÁGIO SUPERVISIONADO PROFISSIONAL I - UFPB).

Trata das concepções metodológicas e abordagens de ensino da educação física na educação infantil e nos primeiros anos do ensino fundamental (1으 ao 5 o ano) vinculadas à intervenção do aluno com a realidade social, econômica e profissional nesse nível de ensino (ESTÁGIO SUPERVISIONADO I - UFRPE, grifo nosso).

Tivemos a percepção de que os estágios têm servido como uma espécie de preparação profissional fundamentada no desempenho de tarefas de ensino que não levam em consideração a especificidade da Educação Infantil. Observamos, também, que, nesta última ementa, da Universidade Federal Rural de Pernambuco, há uma flagrante confusão entre as etapas da Educação Infantil e do Ensino Fundamental que compõem a denominada Educação Básica (BRASIL, 1996), incorrendo no erro de nomeá-las como "nível de ensino".

A especificidade da primeira etapa da Educação Básica deve ser entendida conforme preconizam as DCNEls, de modo que as práticas vivenciadas no cotidiano das instituições devem ser articuladas e não fragmentadas em disciplinas curriculares (como é o caso do Ensino Fundamental e Médio), considerando, de maneira integral e indissociável, as dimensões expressivo-motora, afetiva, cognitiva, linguística, ética, estética e sociocultural das crianças (BRASIL, 2013). A BNCC, embora enfatize a importância de articulação pedagógica 
entre as diferentes etapas da Educação Básica, no sentido de pensar uma trajetória para os escolares, igualmente demarca e ratifica as diferenças que a Educação Infantil preserva em relação às etapas subsequentes.

Uma outra constatação importante é a ausência da palavra "criança" na nuvem (Figura 1). 0 apagamento total do principal sujeito da relação ensino-aprendizagem faz-nos crer que a formação inicial, no que tange às disciplinas de Estágio Supervisionado, está mais preocupada, novamente, com os processos de ensino do que com os da aprendizagem. O foco permanece direcionado à figura do professor e às orientações pertinentes ao fazer docente.

A partir dessa nuvem, buscamos estabelecer as conexões que elas possuem entre si, visualizando-as por meio de análise de similitudes, conforme expresso na Figura 2:

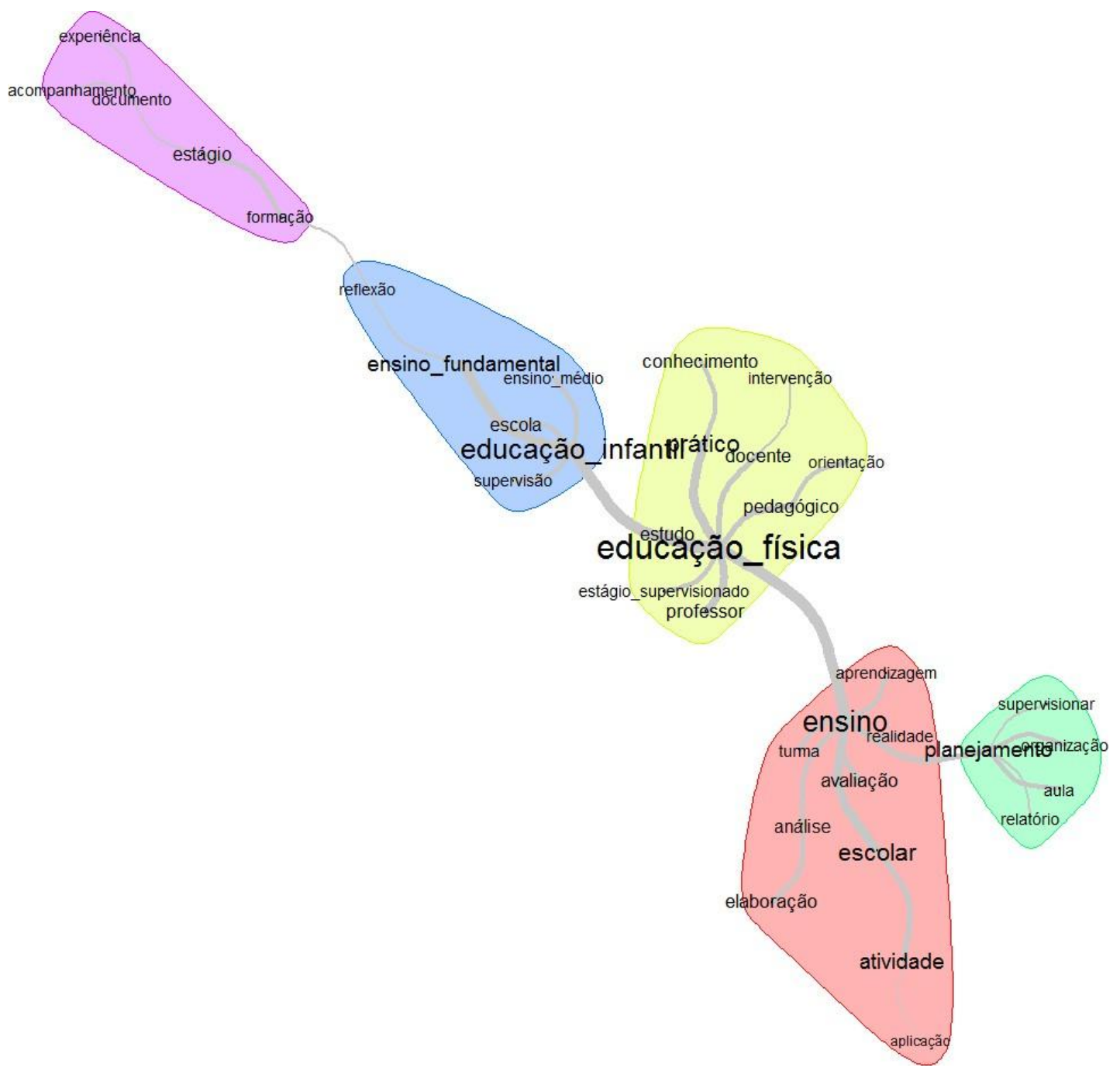

Figura 2 - Similitudes de palavras das ementas das disciplinas de Estágio Supervisionado Fonte: Elaborada pelos autores, 2019.

O recurso da Análise de Similitude permite-nos identificar campos semânticos e conexões constituídas pelas palavras mais citadas no corpus textual examinado. No caso específico da 
Figura 2, foram formados: um núcleo que reúne palavras em torno da expressão "Educação Física"; outro a partir da palavra "ensino"; outro derivado desse núcleo, em torno de "planejamento"; um outro relacionado com a "Educação Infantil", desdobrando-se em "formação", "estágio", "documento", "experiência" e "acompanhamento".

Observando a região azul da figura, na qual se nota a interligação das palavras "Educação Infantil", "Escola", "supervisão", "Ensino Fundamental" e "Ensino Médio", percebemos que a primeira etapa da Educação Básica está assentada na ideia de preparação para as etapas posteriores, corroborando o entendimento anterior exposto na nuvem de palavras e nos excertos das ementas, indicando ausência das especificidades da Educação Infantil. A lógica escolarizante (MARTINS, 2018) também pode ser verificada na região vermelha, na sequência de palavras "ensino", "avaliação", "escolar", "atividade", "aplicação". Por esse ângulo, a relação entre a Educação Infantil e o Ensino Fundamental assemelha-se, de acordo com Moss (2008), à "subordinação" da primeira em relação à segunda, pela qual o sentido preparatório das práticas educativas de uma etapa se condiciona à lógica operativa da outra.

A ausência da palavra "criança" nas ementas que tratam do Estágio Supervisionado, somada à ênfase nos processos diretivos de ensino e de preparação para o Ensino Fundamental (demonstrado nas similitudes e nos excertos), remete-nos à comum confusão do papel da criança com o do aluno. Assim, as crianças passam a ser observadas e problematizadas a partir de sua participação nos seus processos de inserção escolar, muito em função de a escola ser socialmente aceita como a ocupação principal da infância (SIROTA, 2001).

O entendimento presente nas DCNEIs, e reafirmado na BNCC, em sentido contrário, preconiza as crianças como sujeitos de direitos, produtoras de cultura e protagonistas dos seus processos de socialização (BRASIL, 2013). Essa vertente implica o reconhecimento da capacidade de produção simbólica por parte das crianças e a constituição de suas representações e crenças em sistemas organizados, isto é, em culturas.

Em relação às bibliografias relacionadas com essas disciplinas, o Iramuteq formou a seguinte nuvem de palavras, incorporando apenas aqueles autores que são mencionados em pelo menos três obras de sua autoria: 


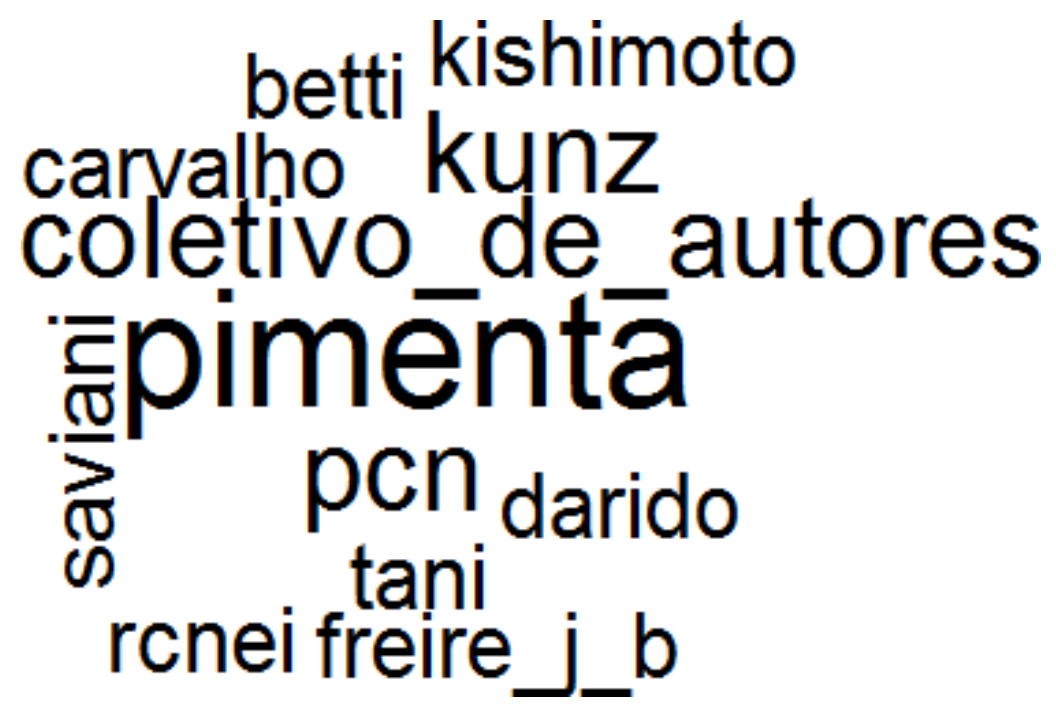

Figura 3 - Nuvem de palavras das bibliografias das disciplinas de Estágio Supervisionado Fonte: Elaborada pelos autores, 2019.

No centro da Figura 3, que aglutina os autores mais utilizados nas bibliografias das disciplinas de Estágio Supervisionado, destaca-se Selma Garrido Pimenta, reconhecida pesquisadora do campo da formação docente. Seus estudos enfatizam a necessidade de articulação entre as dimensões da teoria e da prática nos processos de formação. Entendemos como positiva a dimensão que essa autora ocupa na Figura 3, pois pode ser um índicio de que, pelo menos nas discussões específicas sobre a docência, os pressupostos que a autora defende são considerados, notadamente: a) a instituição de uma práxis pedagógica capaz de promover a construção de conhecimentos com base na ressignificação das teorias a partir dos conhecimentos da prática; b) a pesquisa como eixo central do trabalho pedagógico que fomenta a constituição de uma cultura de análise das práticas a partir das suas problematizações e da realização de projetos de coletivos que envolvem, além dos atores da própria escola, os da universidade (PIMENTA, 2008).

Sobre essa discussão, Martins (2015) afirma que a centralidade das práticas nos processos formativos, a relação colaborativa entre universidade e escolas da Educação Básica e a pesquisa como eixo da formação e atuação docente são pressupostos imprescindíveis para uma formação de professores de Educação Física de atuação profissional na Educação Infantil (balizada na concepção de infância e de criança expressa nas DCNEIs).

O Coletivo de Autores, por meio do livro "Metodologia da Educação Física", de 1992, teve - e ainda tem - ampla repercussão em nossa área, porém não se constitui como um referencial específico do campo da formação docente (o mesmo podemos dizer acerca da autora Darido, também presente na nuvem de palavras). Embora a pré-escola seja mencionada no referido livro, ela não representa a Educação Infantil em si, pois as orientações de organização didático-metodológica elaboradas pelos autores tomam como base os ciclos de escolarização e a seriação dos Ensinos Fundamental e Médio. A preocupação central da obra reside na 
discussão das práticas pedagógicas e na sua operacionalização por parte dos docentes, baseados no materialismo histórico-dialético.

Sobre o impacto dessa proposta para a primeira etapa da Educação Básica, Andrade Filho (2011) assinala que, mesmo quando não utiliza os referenciais Psicomotores e Desenvolvimentistas, a abordagem "crítico-superadora" (COLETIVO DE AUTORES, 1992) aparece com frequência nos discursos dos professores, quando explicitam o modo como organizam o seu trabalho pedagógico, desconsiderando as especificidades da pequena infância e das instituições de ensino destinadas a ela.

A presença dos Parâmetros Curriculares Nacionais (PCNs) (BRASIL, 1998) seria estranha, caso as nuvens de palavras, as similitudes e os excertos das ementas não trouxessem a ideia de progressão e preparação da Educação Infantil para as etapas posteriores da Educação Básica. O PCN é um documento antigo que estabelecia, como o próprio nome indica, parâmetros para a ação pedagógica da Educação Física e as demais disciplinas no Ensino Fundamental e no Ensino Médio. Conforme destacamos nas Figuras 1 e 2, bem como nos excertos das ementas, parece haver uma certa confusão dos papéis específicos que a Educação Infantil e o Ensino Fundamental cumprem no processo de escolarização das crianças.

O Referencial Curricular Nacional para a Educação Infantil (RCNEI) (BRASIL, 1998) destaca-se nas bibliografias das disciplinas de Estágio Supervisionado. Esse documento está ancorado em uma concepção de criança assentada em autores da Psicologia do Desenvolvimento, enquanto as DCNEls e a BNCC mantêm interface com a Sociologia da Infância (MELLO et al., 2016). Mello et al. (2016) avaliam que esses dois últimos avançam em relação ao primeiro, na medida em que

[...] há uma mudança fundamental de concepção, pois a Psicologia preocupase com o que ocorre 'dentro' das crianças em seu desenvolvimento, mesmo que esse processo seja mediado na interação com o social; já a Sociologia da Infância focaliza o que se passa 'entre' elas, direcionando a sua atenção para as produções advindas de suas culturas de pares (MELO et al., 2016, p. 133).

A sua presença em meio às disciplinas dessa natureza pode ser explicada, também, por se constituir como uma proposta curricular, que se assume como um guia prescritivo da ação docente, conforme entendimento de Pinto (2001). Com efeito, o foco dessa disciplina nos cursos de formação de licenciatura em Educação Física, aparentemente, recai sobre os processos diretivos da ação do professor, enfatizando a dimensão do ensino, já observada nas Figuras 1 e 2 (nuvem de palavras e similitudes), em que os termos "intervenção", "atividade", "organização", "avaliação", "aplicação", "supervisionar", "aula" e "aelatório" se destacam pela recorrência e conexidade. 
Tani é outro autor bastante presente nas bibliografias das disciplinas de Estágio Supervisionado. A Educação Física, lastreada por essa premissa, enfatiza a aquisição de habilidades motoras de crescente competência física, condicionada às faixas etárias. As tarefas (atividades intencionais propostas pelo professor) a serem executadas em aula relacionam-se com a capacidade biológica que o indivíduo detém, que, por seu turno, está intimamente ligada ao seu nível de aprendizagem na ocasião, de maneira progressiva da infância (Educação Infantil) para a adolescência (Ensino Fundamental).

A influência de teorias advindas do Comportamento Motor, como é o caso de Tani, diverge da maneira como as DCNEls e a BNCC compreendem o trabalho educativo com o corpo/movimento. Ambos os documentos defendem que a prática pedagógica com o corpo e o movimento está para além da dimensão biológica funcionalista, assumindo uma perspectiva sociocultural que privilegia a produção de sentidos por parte das crianças (MARTINS, 2018).

A aparição de João Batista Freire e de Kishimoto nessa nuvem de palavras faz-nos supor que, de maneira menos incisiva, os jogos e as brincadeiras podem ser entendidos como os possíveis conteúdos que orientam as práticas e discussões sobre esses estágios. Isso, porque os citados autores são reconhecidos pelas suas publicações sobre essas temáticas no campo da Pedagogia e da Educação Física, utilizando os pressupostos da Psicologia do Desenvolvimento e Piagetiana para tal. Soma-se a isso o fato de que o jogo e a brincadeira, segundo Martins, Tostes e Mello (2018), aparecem como conteúdo de ensino privilegiado na formação docente em Educação Física voltada para a Educação Infantil, porém, fortemente marcado por uma visão utilitarista e instrumental desses elementos da cultura corporal. Nesse caso, o jogo e a brincadeira são concebidos como meios para a aquisição de outras aprendizagens consideradas mais importantes, como a leitura e a escrita.

O brincar e o jogar também são dimensões recorrentes nas produções assinadas por Kishimoto. A referida autora trabalha com o conceito de jogo didático (KISHIMOTO, 2008), no qual o ato de jogar se torna um eixo que conduz a um conteúdo pedagógico específico, resultando em um empréstimo da ação lúdica para a aquisição de informações consideradas relevantes ao modelo escolar estabelecido (MARTINS, 2018).

Assim como Corsaro (2005), acreditamos que os estudos sobre a infância precisam superar os modelos homogeneizantes, muito utilizados pelo campo da Pedagogia, advindos da Psicologia do Desenvolvimento, que estabelecem padrões universais e preconcebidos para se compreender os processos de desenvolvimento das crianças. De acordo com esse autor, as crianças são produtoras de suas infâncias, sujeitos capazes de criar e modificar aspectos culturais diretamente ligados à reprodução interpretativa, em que elas são consideradas como atores sociais, sujeitos de direitos, protagonistas nos seus mundos de vida particulares ou na escola. 
Concordamos com Pinto (2001) que afirmar que, nos cursos de licenciatura em Educação Física, parece haver pouco debate e pouca reflexão sobre o papel social e cultural da infância. Para a autora, "[...] essa discussão, quando existe, enfatiza os aspectos funcionais do jogo, da brincadeira e do movimento, privilegiando a abordagem instrumental desses conteúdos" (PINTO, 2001, p. 141). Esse argumento fortalece a ideia de que os pressupostos que compreendem a infância e as crianças sob a ótica utilitarista têm orientado a intervenção dos profissionais nessa etapa de ensino, bem como divergido das contribuições oferecidas pela BNCC e pelas DCNEIs.

A BNCC e as DCNEls apontam o jogo e a brincadeira como construções sociais pertencentes ao universo identitário da infância. Para Martins (2018), a presença e a influência da Psicologia nas produções acadêmicas da Educação Física, com foco na Educação Infantil, especialmente pela abordagem construtivista desenvolvida por João Batista Freire, em função da sua concepção teórica, divergem do preconizado pelas DCNEls e pela BNCC, estando mais afinadas com a noção de jogo/brincadeira encontrada no RCNEl.

\section{CONSIDERAÇÕES FINAIS}

Discutimos neste artigo em que medida as disciplinas de Estágio Supervisionado voltadas para a Educação Infantil nos cursos de Educação Física se aproximam ou se distanciam dos documentos orientadores da primeira etapa da Educação Básica, problematizando, portanto, a docência no Ensino Superior e o diálogo com as demandas do campo profissional.

Em síntese, percebemos que há um descompasso entre o modo como a formação de professores está estruturada nos cursos de licenciatura em Educação Física, sobretudo, na sistematização das experiências com o cotidiano da Educação Infantil mediadas pelas disciplinas curriculares de Estágio Supervisionado, e as demandas do campo de atuação profissional expressas pelos/nos documentos oficiais orientadores da ação docente na Educação Básica. Assim, chegamos ao entendimento de que, nas IES pesquisadas, os cursos de formação inicial em Educação Física vêm reproduzindo concepções de criança/infância, corpo/movimento e de jogos/brincadeiras pautadas em aspectos distantes do que preconizam as DCNEls e a BNCC.

Observamos haver um afastamento do conteúdo das ementas e das bibliografias das 14 disciplinas analisadas com relação à produção acadêmica e aos documentos oficiais que balizam o trabalho pedagógico na Educação Infantil no país. Esse distanciamento pode acarretar dificuldades para a ampliação da presença do professor com formação em Educação Física na primeira etapa da Educação Básica e, também, para a sua permanência, na medida em que os indícios captados nesses dados divergem frontalmente das concepções de infância/criança e de jogos/brincadeiras trazidas tanto na BNCC quanto nas DCNEIs. 
É importante frisar que esses mesmos documentos ressaltam que os jogos e as brincadeiras são elementos centrais nos processos de ensino-aprendizagem na Educação Infantil. Em nossa avaliação, esses elementos dialogam intimamente com os sabaresfazeres (ALVES, 2010) da Educação Física. Portanto, resta à IES (re)discutir o modo como o Estágio Supervisionado está estruturado, levando em consideração a concepção de infância e de organização didáticocurricular que caracteriza a Educação Infantil, no sentido de alinhar as contigências do campo profissional à formação em Educação Física para a atuação nas insitituições educativas da primeira infância.

As análises empreendidas mostraram que as ementas indicam a Educação Infantil como sendo etapa preparatória para o Ensino Fundamental, lastreada por uma lógica escolarizante (MARTINS, 2018), em que a ação diretiva da atividade docente assume centralidade na formação providenciada por meio do Estágio Supervisionado. Em relação aos referenciais teóricos dessas disciplinas, os documentos oficiais e os autores de destaque assumidos como bibliografia estão ligados à Psicologia do Desenvolvimento e Piagetiana. Além disso, são pertencentes ao Comportamento Motor. Eles distanciam-se das perspectivas anunciadas nas DCNEIs e na BNCC, por serem campos marcados por ações diretivas, que tomam a criança com alvo destinatário da ação adulta (docente), sem reconhecê-la como sujeito dotado de direitos, que tem interesses, anseios e necessidades que precisam ser respeitados e considerados nos processos educativos.

Portanto, é preciso que haja atuação profissional de maneira mais alinhada com uma concepção de infância que traga a criança para o centro da ação pedagógica e que a mediação se dê, fundamentalmente, pelas experiências decorrentes das relações estabelecidas entre as crianças e delas com os adultos, evitando, assim, a assunção de perspectivas que desconsiderem as singularidades da infância, as expectativas e as necessidades das crianças. Caso contrário, a presença do professor de Educação Física na Educação Infantil pode ser posta em xeque.

A nosso ver, essa discussão não se esgota nas análises empreendidas neste artigo. Ao contrário, necessita ser ampliada para a análise do currículo e respectivas ementas/bibliografias de outras universidades para além daquelas situadas em capitais brasileiras em que já há a presença de professores de Educação Física atuando profissionalmente no magistério público municipal com a Educação Infantil.

\section{REFERÊNCIAS}

ALVES, Nilda. Sobre as razões das pesquisas nos/dos/com os cotidianos. In: GARCIA, Regina Leite (org.). Diálogos cotidianos. Petrópolis, RJ: DPA et ali, 2010. p. 67-82.

ANDRADE FILHO, Nelson Figueiredo de. Experiências de movimento corporal de crianças no cotidiano da educação infantil. 2011. Tese (Doutorado em Educação) - Programa de Pós- 
Graduação em Educação, Faculdade de Educação, Universidade Estadual de Campinas, Campinas-SP, 2011.

BISCOSNI, Camila Rinaldi; OLIVEIRA, Amauri Aparecido Bassoli. O estágio curricular supervisionado na formação inicial para a docência: as significações dos estagiários como atores do processo. Motrivivência, Florianópolis, v. 28, n. 4, p. 347-359, set. 2016. Disponível em: https://doi.org/10.5007/2175-8042.2016v28n48p347. Acesso em: 20 jul. 2019.

BRASIL. Congresso Nacional. Lei no 9394/96, de 20 de dezembro de 1996. Lei de Diretrizes e Bases Da Educação Nacional. Diário Oficial [da] República Federativa do Brasil, Brasília, 23 dez. 1996.

BRASIL. Ministério da Educação e do Desporto. Referencial Curricular Nacional para a Educação Infantil. Brasília: MEC/SEF, 1998.

BRASIL. Ministério da Educação e do Desporto. Secretaria da Educação Média e Tecnológica. Parâmetros Curriculares Nacionais: Ensino Fundamental. Brasília/DF: MEC, 1998.

BRASIL. Ministério da Educação. Diretrizes Curriculares Nacionais Gerais da Educação Básica. Brasília: Secretaria de Educação Básica. Diretoria de Currículos e Educação Integral, 2013.

BRASIL. Ministério da Educação. Base Nacional Comum Curricular. Brasília: MEC, 2017. Disponível em: http://basenacionalcomum.mec.gov.br/\#/site/inicio. Acesso em: 10 mar. 2019.

CAMARGO, Brigídio Vizeu; JUSTO, Ana Maria. Tutorial para uso do software de análise textual IRAMUTEQ. Florianópolis: Laboratório de Psicologia Social da Comunicação e Cognição - Laccos da Universidade Federal de Santa Catarina, 2013.

COLETIVO DE AUTORES. Metodologia do ensino de Educação Física. São Paulo: Cortez, 1992.

CORSARO, William. Entrada no campo, aceitação e natureza da participação nos estudos etnográficos com crianças pequenas. Educação \& Sociedade, v. 26, n. 91, p. 443- 464, maio/ago. 2005. Disponível em: http://dx.doi.org/10.1590/S0101-73302005000200008. Acesso em: 15 jul. 2019.

KISHIMOTO, Tizuko Morchida. O jogo, brinquedo, brincadeira e a educação. 11. ed. São Paulo: Cortez, 2008.

MARTINS, Rodrigo Lema Del Rio. O Pibid e a formação docente em Educação Física para a Educação Infantil. 2015. Dissertação (Mestrado em Educação Física) - Programa de PósGraduação em Educação Física, Universidade Federal do Espírito Santo, Vitória-ES, 2015.

MARTINS, Rodrigo Lema Del Rio. O lugar da Educação Física na Educação Infantil. 2018. Tese (Doutorado em Educação Física) - Programa de Pós-Graduação em Educação Física, Universidade Federal do Espírito Santo, Vitória-ES, 2018. 
MARTINS, Rodrigo Lema Del Rio; TOSTES, Luiza Fraga; MELLO, André da Silva. Educação infantil e formação docente: análise das ementas e bibliografias de disciplinas dos cursos de educação física. Movimento, Porto Alegre, v. 24, p. 10-23, 2018. Disponível em: https://doi.org/10.22456/1982-8918.77519. Acesso em: 18 jul. 2019.

MELLO, André da Silva et al. Educação Física na Educação Infantil: um estudo em periódicos da área. In: MELLO, André da Silva; SANTOS, Wagner (org.). Educação física na Educação Infantil: práticas pedagógicas no cotidiano escolar. Curitiba: Editora CRV, 2012. p. 41-56.

MELLO, André da Silva et al. Educação Infantil a e Base Nacional Comum Curricular: interfaces com a educação física. Motrivivência, Florianópolis, v. 28, n. 48, p. 130-149, set. 2016. Disponível em: https://doi.org/10.5007/2175-8042.2016v28n48p130. Acesso em: 18 jul. 2019.

MOSS, Peter. What future for the relationship between early childhood education and care and compulsory schooling? Research in Comparative and International Education, v. 3, n. 3, 2008. Disponível em: https://doi.org/10.2304/rcie.2008.3.3.224. Acesso em: 15 jul. 2019.

PIMENTA, Selma Garrido. Professor reflexivo: construindo uma crítica. In: PIMENTA, Selma Garrido; GHEDIN, Evandro. (org.). Professor reflexivo no Brasil: gênese e crítica de um conceito. 5. ed. São Paulo: Cortez, 2008. p. 17-52.

PIMENTEL, Alessandra. O método da análise documental: seu uso numa pesquisa historiográfica. Cadernos de Pesquisa, São Paulo, n. 114, p. 179-195, nov. 2001. Disponível em: http://dx.doi.org/10.1590/S0100-15742001000300008. Acesso em: 17 jul. 2019.

PINTO, Rubia-Mar Nunes. A formação de professores para a Educação Infantil: desafios para a universidade. Pensar a Prática, Goiânia, v. 4, p. 135-148, jun./jul. 2001. Disponível em: https://doi.org/10.5216/rpp.v4i0.82. Acesso em: 20 jul. 2019.

SIROTA, Règine. Emergência de uma sociologia da infância: evolução do objeto e do olhar. Cadernos de Pesquisa, n. 112, p. 7- 31, mar. 2001. Disponível em:

http://dx.doi.org/10.1590/S0100-15742001000100001. Acesso em: 18 jul. 2019.

TARDIF, Maurice. Saberes docentes \& formação profissional. 8. ed. Petrópolis, RJ: Vozes, 2007. 


\section{Rodrigo Lema Del Rio Martins}

Doutor em Educação Física pela Universidade Federal do Espírito Santo (UFES-2018).

Licenciado Pleno em Educação Física pela Universidade Federal Rural do Rio de Janeiro

(UFRRJ-2006). Professor do curso de Educação Física da Universidade Federal do Tocantins

(UFT). Líder do Núcleo de Aprendizagens com as Infâncias e seus Fazeres (NAIF/UFES) e do

Grupo de Investigação Pedagógica em Educação Física (GIPEF/UFT).

rodrigodrmartins@uft.edu.br

\section{Luiza Fraga Tostes}

Licenciada em Educação Física pela Universidade Federal do Espírito Santo (UFES - 2019).

Mestranda em Educação Física na UFES (2020-atual). Bolsista de Iniciação à Docência - PIBID (2015/2016). Bolsista de Iniciação Científica - PIBIC/CNPq (2016/2017 e 2017/2018). Membro do Núcleo de Aprendizagens com as Infâncias e seus Fazeres (NAIF/UFES).

lufragatostes@gmail.com

\section{André da Silva Mello}

Licenciado pleno em Educação Física pela Universidade Federal do Espírito Santo (1993); Doutor em Educação Física pela Universidade Gama Filho (2007); e Pós-Doutorado pelo Programa Associado em Educação Física da UEM/UEL (2019). Professor no Programa de Pósgraduação em Educação Física da UFES. Líder do Núcleo de Aprendizagens com as Infâncias e seus Fazeres (NAIF/UFES).

andremellovix@gmail.com 